\title{
Comunicación
}

\section{Presencia emergente de Pasteurella bettyae en el aparato genital de una mujer}

\author{
Emerging presence of Pasteurella bettyae in a woman's genital tract
}

Cristina Gómez-Camarasa ${ }^{1}$, Carla Foronda-García-Hidalgo ${ }^{1}$, Jaime Borrego Jiménez $^{1}$, Jorge Fernández-Parra ${ }^{2}$, José Gutiérrez-Fernández ${ }^{1,3,4}$

\section{Resumen}

Se describe un caso clínico donde se demuestra la presencia de Pasteurella bettyae en un exudado endocervical en una paciente de 45 años, pero no se puede asegurar como la causa única de la infección. Su presencia puede indicar una colonización, aunque este microorganismo no es reconocido como parte de la microbiota humana. A pesar de su rareza, gracias a la prueba de Maldi-Tof aplicada a colonias que crecen en medios de cultivo, es posible conocer la presencia infrecuente de este tipo de microorganismo.

Palabras clave: infección genital, Pasteurella bettyae, infección emergente

\section{AbSTRaCT}

A clinical case is described where the presence of Pasteurella bettyae in an endocervical exudate in a 45-year-old patient is demonstrated, but it cannot be assured as the sole cause of the infection. Its presence may indicate a colonization, although this microorganism is not recognized as part of the human microbiota. Despite its rarity, thanks to the Maldi-Tof test applied to colonies that grow in culture media, it is possible to know the infrequent presence of this type of microorganism.

Key words: genital infection, Pasteurella bettyae, emerging infection

${ }^{1}$ Servicio de Microbiología, Hospital Universitario Virgen de las Nieves, Instituto de Investigación Biosanitaria de Granada, Granada, España

${ }^{2}$ Unidad de Gestión Clínica de Obstetricia y Ginecología, Hospital Universitario Virgen de las Nieves, Instituto de Investigación Biosanitaria de Granada. Granada, España

${ }^{3}$ Departamento de Microbiología, Facultad de Medicina, Universidad de Granada, Instituto de Investigación Biosanitaria de Granada, Granada, España

${ }^{4}$ Email:josegf@go.ugr.es

Recibido: 20 de abril de 2019

Aceptado para publicación: 18 de enero de 2020

Publicado: 31 de marzo de 2020 


\section{INTRODUCCIÓN}

Pasteurella spp son bacterias patógenas que colonizan la boca de gatos y perros y, como tal, se asocian principalmente con infecciones cutáneas y de tejidos blandos en humanos como consecuencia de mordeduras de animales. De forma menos frecuente pueden ocasionar infecciones en las vías respiratorias, superiores e inferiores, e infecciones más graves, como meningitis, bacteriemia, endocarditis, peritonitis, así como en los huesos y articulaciones de manera secundaria (Costanzo et al., 2017). También se ha descrito transmisión indirecta por transfusión sanguínea, transplacentaria o por contacto directo con personas colonizadas (Zarlasht y Khan, 2018).

Pasteurella multocida es la principal especie productora de infecciones, pero hay que tener en cuenta que otras especies del género, como Pasteurella bettyae, pueden potencialmente producir infecciones en el humano. Se presenta un caso de infección genital por $P$. bettyae en una paciente inmunocompetente.

\section{Caso Cuínico}

Se trató de una paciente de 45 años que acude a urgencias por referir leucorrea desde hace dos semanas. Entre los antecedentes personales a destacar solo refiere tener una sola pareja sexual y un gato en casa. Se le tomaron exudados, a nivel endocervical y vaginal para estudio de agentes genitopatógenos, así como serología para $\mathrm{VIH}$, hepatitis $\mathrm{B}$, hepatitis $\mathrm{C}$ y sífilis. Así mismo, se le administró ceftriaxona ( $250 \mathrm{mg}$ i.m.) y azitromicina $(1 \mathrm{~g}$, v.o. $)$ para seguimiento por su médico de cabecera.

Siguiendo con el protocolo normalizado de trabajo del Laboratorio de Microbiología del hospital para los exudados endocervicales, se realizó siembra en medios de cultivos se- lectivos para gonococos y levaduras (BectonDickinson, España), y en medios de cultivo no selectivos, agar sangre y agar chocolate (Becton-Dickinson), así como pruebas de PCR para detectar Chlamydia trachomatis, Neisseria gonorrhoeae, Mycoplasma genitalium, Mycoplasma hominis, Ureaplasma urealyticum y Ureaplasma parvum (BD Max, Becton-Dickinson Diagnostics, Sparks, USA) (Hidalgo-Chicharro et al., 2017; Sorlózano-Puerto et al., 2018), obteniendo un resultado positivo para M. hominis y U. parvum.

Con el exudado vaginal se realizó, mediante técnica de hibridación, la detección de Candida spp, Trichomonas vaginalis $\mathrm{y}$ Gardnerella vaginalis (Becton-Dickinson Diagnostics, Sparks) que dio positivo a $G$. vaginalis. En el cultivo del exudado endocervical crecieron, además, abundantes colonias, de forma única, que se identificaron mediante Maldi-Tof(Bruker Biotyper, Billerica, USA), con un score 2100, como $P$. bettyae, sensible a ampicilina (CMI $0.19 \mu \mathrm{g} / \mathrm{ml}$ ), amoxicilina-clavulánico (CMI $0.125 \mu \mathrm{g} / \mathrm{ml}$ ), trimetoprim/sulfametoxazol (CMI $0.19 \mu \mathrm{g} / \mathrm{ml}$ ) y doxicilina (CMI $0.38 \mu \mathrm{g} / \mathrm{ml}$ ) y resistente a ciprofloxacino (CMI $0.38 \mu \mathrm{g} / \mathrm{ml}$ ), realizándose el antibiograma mediante la técnica de Etest, interpretado según los criterios del documento M45 del Clinical \& Laboratory Standards Institute (CLSI, 2015). Todos los resultados de la serología fueron negativos. La paciente no volvió a acudir a la consulta por lo que se desconoce su evolución.

\section{Discusión}

Pasteurella spp son bacterias no móviles, aerobias-anaerobias facultativas, que crecen en agar chocolate y agar sangre, pero no en agar MacConkey. No causan hemólisis en agar sangre, $\mathrm{y}$ crecen mejor en medio rico en dióxido de carbono a $37^{\circ} \mathrm{C}$. Casi todos los casos de infección descritos son producidos por P. multocida y evidencian exposición o contacto previo con animales. El con- 
tacto benigno con animales (besos o lamidas en abrasiones o en mucosas) puede incluso llegar a provocar una infección, aunque también se reportan infecciones sin exposición previa reconocida (Narsana y Farhat, 2015). La mayoría de las infecciones humanas descritas son de heridas, asociadas con mordeduras y arañazos de gatos y perros; sin embargo, el espectro clínico de las infecciones por $P$. multocida también puede incluir infecciones profundas. Las infecciones genitourinarias por este microorganismo son raras (Singh y Harrington, 2017).

$P$. bettyae se ha aislado menos frecuentemente de muestras genitourinarias (como exudados de úlcera genitales, quistes de Bartolino, exudados vaginales, orina, líquido amniótico y placenta) y en hemocultivos de recién nacidos como resultado de una probable transmisión durante el parto (Moritz et al., 1996; Shapiro et al., 1996; De León et al., 2000; Gómez-Canmarasa et al., 2015). Es posible que la clínica de la paciente sea debido a la combinación de los múltiples agentes detectados: $G$. vaginalis, $P$. bettyae y $M$. hominis. U. parvum suele ser un colonizante genital de interés en las pacientes con rotura prematura de membranas. El aislamiento de $P$. bettyae en los exudados genitales de esa paciente podría ser una colonización (de una muestra que nunca es estéril), y, con el hallazgo de al menos dos agentes más con potencial carácter patogénico, hace difícil o imposible determinar su papel patogénico en este caso. No obstante, la presencia abundante y monomicrobiana en el cultivo permite resaltar el valor de $P$. bettyae en el cuadro clínico de la paciente.

En la actualidad se vienen observando cambios epidemiológicos en la etiología de las infecciones del aparato genital, lo que determinará una actuación diagnóstica más completa, haciendo peticiones analíticas más amplias y adecuando los procedimientos diagnósticos disponible a las necesidades clínicas. Gracias a las técnicas de Maldi-Tof, la identificación de este tipo de agentes es fácil y rápida en los laboratorios de microbiología clínica. El estudio microbiológico con cultivo para agentes bacterianos exigentes (Hidalgo-Chicharro et al., 2017), y la PCR para la detección del virus del herpes simple, Mycoplasma, Ureaplasma, Neisseria gonorrhoeae y $C$. trachomatis, y su tipado cuando sea posible, se consideran pruebas necesarias para realizar. Que el hallazgo sea inhabitual es un motivo de interés, sobre todo porque modifica los conocimientos previos sobre la necesidad de cambios en el estudio microbiológico estándar, manejo clínico y tratamiento de las infecciones genitales.

El tratamiento de elección es penicilina, aunque se han descrito resistencias, en cuyo caso se trataría con cefalosporinas de segunda o tercera generación, fluorquinolonas y/o tetraciclina (Zarlasht y Khan, 2018). En el presente caso se desconoce la evolución de la paciente tras el tratamiento inicial.

Como conclusión, se describe un nuevo caso de la presencia de $P$. bettyae en un exudado endocervical de una paciente; aunque, con base a los datos expuestos, no se puede asegurar como la causa única de la infección, y su presencia puede indicar una colonización. A pesar de su rareza, gracias a la técnica de Maldi-Tof aplicada a colonias creciendo en medios de cultivo, es posible conocer la presencia infrecuente de este tipo de microorganismos.

\section{Literatura Citada}

1. [CLSI] Clinical \& Laboratory Standards Institute. 2015. M45. Methods for antimicrobial dilution and disk susceptibility testing of infrequently isolated or fastidious bacteria. $3^{\text {rd }}$ ed. USA: CLSI. 97 p.

2. Costanzo JT, Wojciechowski AL, Bajwa RPS. 2007. Urinary tract infection with Pasteurella multocida in a patient with cat exposure and abnormal urinary tract physiology: case report and literature review. IDCases 9: 109-111. doi: 10.1016/j.idcr.2017.07.002 
3. De Leon JP, Sandfort RF, Wong JD. 2000. Pasteurella bettyae: report of nine cases and evidence of an emerging neonatal pathogen. Clin Microbiol News 22: 190-192. doi: 10.1016/S01964399(01)80009-X

4. Gómez-Camarasa C, Liébana-Martos C, Navarro-Marí JM, GutiérrezFernández J. 2015. Detection of unusual uropathogens during a period of three years in a regional hospital. Rev Esp Quim 28: 86-91.

5. Hidalgo-Chicharro A, AbadTorreblanca R, Navarro-Marí JM, Gutiérrez-Fernández J. 2017. 32week premature rupture of membranes caused by oropharyngeal microbiota. JMM Case Rep 4: e0051214. doi:10.1099/jmmcr.0.005121

6. Moritz F, Martin E, Lemeland JF, Bonmarchand G, Leroy J, Escande F. 1996. Fatal Pasteurella bettyae pleuropneumonia in a patient infected with human immunodeficiency virus. Clin Infect Dis 22: 591-592. doi: 10.1093/ clinids/22.3.591
7. Narsana N, Farhat F. 2015. Septic shock due to Pasteurella multocidabacteremia: a case report. J Med Case Rep 9: 159. doi: 10.1186/s13256-015-0643-3

8. Shapiro DS, Brooks PE, Coffey DM, Browne KF. 1996. Peripartum bacteremia with CDC group HB-5 (Pasteurella bettyae). Clin Infect Dis 22: 11251126. doi: $10.1093 /$ clinids/22.6.1125

9. Singh MB, Harrington AT. 2017. Pasteurella multocida urinary tract infection in a patient with cervical cancer. JMM Case Rep 4: e005082. doi: 10.1099/jmmcr.0.005082

10. Sorlózano-Puerto A, Esteban-Sanchis P, Heras-Cañas V, Fernández-Parra J, Navarro-Marí JM, GutiérrezFernández J. 2018. Estudio prospectivo de la incidencia de patógenos genitales oportunistas y estrictos que crecen en medios de cultivo artificiales. Rev Lab Clín 11: 123-130. doi: 10.1016/ j.labcli.2017.11.009

11. Zarlasht F, Khan M. 2018. A case of recurrent Pasteurella bacteremia in an immunocompetent patient with no animal bite. Am J Case Rep 19: 95-98. doi: 10.12659/ajcr.907251 